\title{
Multiplex polymerase chain reaction detection of Streptococcus pneumoniae and Haemophilus influenzae and their antibiotic resistance in patients with community-acquired pneumonia from southwest Iran
}

\author{
Ahmad Farajzadeh Sheikh ${ }^{1,2}$, Robab Rahimi ${ }^{1,2^{*}}$, Hossein Meghdadi ${ }^{1,2,3^{*}}$, Ameneh Alami ${ }^{1,2}$ and Morteza Saki ${ }^{1,2,3^{*}}$
}

\begin{abstract}
Background: This study aimed to evaluate the occurrence of Streptococcus pneumoniae and Haemophilus influenzae in sputum of patients with community-acquired pneumonia (CAP) using culture and multiplex polymerase chain reaction (M-PCR) methods and to survey the antibiotic resistance patterns of aforesaid isolates.

Result: In total, $23.9 \%(n=22 / 92)$ of sputum samples showed positive results in the culture method. S. pneumoniae and $H$. influenzae were isolated from 15 (16.3\%) and 7 (7.6\%) samples, respectively. Using M-PCR, 44 (47.8\%) samples were positive for S. pneumoniae and H. influenzae. Of these, S. pneumoniae and H. influenzae were detected in 33 (35.8\%) and 11 (11.9\%) of the sputum samples, respectively. The sensitivity, specificity, and accuracy rates of PCR in detection of S. pneumoniae in comparison with culture method were 100,76.6, and 83.6\%, respectively. While, the sensitivity, specificity, and accuracy rates of PCR in detection of $\mathrm{H}$. influenzae in comparison with culture method were 100,95.3, and 95.8\%, respectively. Out of 11 isolates of H. influenzae, two strains confirmed as H. influenzae type b (Hib) and 3 isolates were type f. However, 6 isolates were non-typable. The cotrimoxazole and amoxicillin/clavulanate were the less effective antibiotics against S. pneumonia and $H$. influenzae, respectively. Ceftriaxone with $13.3 \%$ resistance rates was the most effective antibiotic against $S$. pneumoniae, while, clarithromycin, ceftriaxone, and gentamicin with resistance rates of $28.6 \%$ for each one were the most effective chemicals against $H$. influenzae isolates.

Conclusion: In this study, the prevalence of S. pneumoniae was more than H. influenzae using culture and M-PCR methods. The M-PCR provided better efficiency in detecting the bacterial agents in CAP patients compared to culture method. This method can improve the early detection of pathogens contributed to CAP. The drug resistant S. pneumoniae and $H$. influenzae indicated the need to develop a codified monitoring program to prevent further spread of these strains.
\end{abstract}

Keywords: Community-acquired pneumonia, CAP, Haemophilus influenzae, Multiplex polymerase chain reaction, Streptococcus pneumoniae

*Correspondence: rahimirobab@gmail.com; H.meghdadi20@gmail.com; mortezasaki1981@gmail.com

1 Department of Microbiology, Faculty of Medicine, Ahvaz Jundishapur

University of Medical Sciences, Ahvaz, Iran

${ }^{3}$ Student Research Committee, Ahvaz Jundishapur University of Medical Sciences, Ahvaz, Iran

Full list of author information is available at the end of the article

(c) The Author(s) 2021, corrected publication 2022. Open Access This article is licensed under a Creative Commons Attribution 4.0 International License, which permits use, sharing, adaptation, distribution and reproduction in any medium or format, as long as you give appropriate credit to the original author(s) and the source, provide a link to the Creative Commons licence, and indicate if changes were made. The images or other third party material in this article are included in the article's Creative Commons licence, unless indicated otherwise in a credit line to the material. If material is not included in the article's Creative Commons licence and your intended use is not permitted by statutory regulation or exceeds the permitted use, you will need to obtain permission directly from the copyright holder. To view a copy of this licence, visit http://creativecommons.org/licenses/by/4.0/. The Creative Commons Public Domain Dedication waiver (http://creativecommons.org/publicdomain/zero/1.0/) applies to the data made available in this article, unless otherwise stated in a credit line to the data. 


\section{Background}

Over 3 million deaths each year are caused by community-acquired pneumonia (CAP). Also, this infection remains a major challenge to physicians because the highest mortality rates occur in the first days of patient admission [1, 2]. Streptococcus pneumoniae and Haemophilus influenzae are two main bacteria that contributed to CAP [3]. Although many pathogens can cause CAP, S. pneumoniae is the most commonly reported bacterium among adults and young children [4]. This Gram-positive pathogen can colonize the nasopharyngeal region without causing significant clinical indications. In developing and underdeveloped nations, S. pneumoniae causes more than 14 million invasive infections and nearly one million mortalities in children each year [5].

$H$. influenzae is the second most frequently reported bacterium in patients with CAP. This Gram-negative bacterium exists in two forms: encapsulated (typeable) and unencapsulated (non-typeable) $H$. influenzae (NTHi) $[6,7]$. Encapsulated $H$. influenzae includes 6 serotypes a, b, c, d, e and f [810]. H. influenzae type $\mathrm{b}$ (Hib) is a prevalent cause of serious illness, practically in children under the age of 5 years. Before vaccination, the majority of cases of bacterial meningitis in children under 5 years of age were due to Hib, with more than $83 \%$ of cases occurring in children under 2 years of age. While the number of cases of Hib has decreased significantly over the last three decades, its impact is still significant. Approximately 340,000 severe cases of Hib infection were reported globally in 2015 among children aged under 5 years old, with most cases (76\%) manifesting as pneumonia and 29,600 deaths linked to the Hib infection [9].

As the CAP infection is life-threatening, rapid laboratory diagnosis and immediate treatment is important to control the disease and save the patient life. The culture method is the gold standard in the detection of bacterial pathogens that cause CAP infection. However, it has some limitations. First, it is time-consuming (24-72 h) and the second is low bacterial growth in people who have received antibiotics [11, 12]. Hence, using molecular techniques such as polymerase chain reaction (PCR) that are rapid and sensitive, can improve the speed and accuracy of detection of CAP pathogens [13].

Although the antibiotic resistance has increased in most parts of the world and among different bacteria, the true extent of antibiotic non-susceptibility among respiratory pathogens in southwestern Iran has not been well studied. Recent studies from China [14] and Taiwan [15] have reported the emergence of multidrug-resistant S. pneumoniae and $H$. influenzae strains.

This study aimed to evaluate the occurrence of $S$. pneumoniae and $H$. influenzae and their antibiotic resistance patterns in sputum samples of patients with CAP from southwest Iran.

\section{Materials and methods}

\section{Ethics statement}

This study was approved by the Research Ethics Committee (IR.AJUMS.REC.1394.458) of the Ahvaz Jundishapur University of Medical Sciences, Ahvaz, Iran following the Declaration of Helsinki. Written informed consent was obtained from each patient before collecting sputum samples.

\section{Sample collection}

This cross-sectional study was conducted during the two years 2014 to 2016 at the teaching hospitals of Ahvaz city, southwest Iran. The diagnosis of CAP patients was confirmed by specialists in respiratory and lung infectious diseases of the hospitals. Ninety-two sputum samples were collected from patients who were selected based on their clinical symptoms, chest $\mathrm{x}$-ray, and laboratory tests including positive C-reactive protein (CRP), elevated procalcitonin, and leukocytosis. Inclusion criteria were the presence of pneumonia on the basis of a clinical assessment including fever, cough, sputum production, pleuritic chest pain, and dyspnea. Patients who got antibiotic therapy within the last three days were excluded from this study.

\section{Culture and microbiologic testing}

The sputum samples were taken in a sterile container and were transported to the laboratory within less than one hour and immediately analyzed microscopically by Gram staining. The samples that had more than 25 polymorphonuclear cells and less than 10 epithelial cells per low power field were included in this study as suitable sputum samples. After Gram staining and direct microscopic examination, sputum samples were cultured on sheep blood agar and chocolate agar (Merck, Germany) and incubated at $35{ }^{\circ} \mathrm{C}$ with 5 to $10 \% \mathrm{CO}_{2}$. After 48 hours of incubation, the suspected colonies of S. pneumoniae and $H$. influenzae were identified by a panel of standard biochemical and bacteriological tests. For S. pneumonia, Gram staining, colony morphology, catalase, hemolysis on blood agar plate, bile solubility, and optochin tests were included. For $H$. influenzae, Gram staining, colony morphology, growth on chocolate agar, oxidase, $\mathrm{X}$ factor (hemin) and $\mathrm{V}$ factor (nicotinamide-adenine-dinucleotide, NAD) requirement were included [16]. 


\section{Antibiotic susceptibility test}

Antimicrobial susceptibility testing was carried out using disc diffusion method according to the Clinical and Laboratory Standards Institute (CLSI) guidelines [17]. The following antibiotics were used for S. pneumoniae: ceftriaxone (CRO, $30 \mu \mathrm{g})$, erythromycin (ERY, $15 \mu \mathrm{g}$ ), co-trimoxazole (SXT, 1.25/23.75 $\mu \mathrm{g}$ ), clarithromycin (CLR, 15 $\mu \mathrm{g}$ ), and amoxicillin/clavulanate (AMC, 20/10 $\mu \mathrm{g}$ ). Also, the following antibiotics were used for $H$. influenzae: ceftriaxone (CRO, $30 \mu \mathrm{g})$, co-trimoxazole (SXT, 1.25/23.75 $\mu \mathrm{g})$, clarithromycin (CLR, $15 \mu \mathrm{g})$, and amoxicillin/clavulanate (AMC, 20/10 $\mu \mathrm{g}$ ). Mueller-Hinton agar (Merck, Germany) with $5 \%$ sheep blood and Haemophilus test medium (HTM) (Condalab, Spain) were used for S. pneumonia and $H$. influenzae, respectively.

\section{Multiplex polymerase chain reaction (M-PCR) technique}

DNA extraction was performed from sputum samples by High Pure PCR Template Preparation Kit (Roche Diagnosis, Mannheim, Germany) according to manufacturers, instructions. The primers used for M-PCR were specific for lytA gene (395bp) of S. pneumoniae and P6 protein (273bp) of $H$. influenzae (Table 1) [18, 19]. The PCR reaction composed of $0.5 \mu \mathrm{l}$ of each primer, $12.5 \mu \mathrm{l}$ of Mastermix [ $50 \mathrm{mM} \mathrm{KCl}, 10 \mathrm{mmol}$ Tris- $\mathrm{HCl}(\mathrm{pH} 8.3)$, $0.2 \mathrm{mM}$ each dNTP, $1.5 \mathrm{mM} \mathrm{MgCl}_{2}$, $1 \mathrm{U}$ Taq DNA polymerase] (Genet Bio, Korea), $5 \mu \mathrm{l}$ of template DNA, and DNA/RNA free water to reach the final volume of $25 \mu$ l. The programs of PCR were as follows: 5 minutes at $95^{\circ} \mathrm{C}$ followed by 35 cycles (denaturation at $95{ }^{\circ} \mathrm{C}$ for $30 \mathrm{sec}$ onds, annealing at $54{ }^{\circ} \mathrm{C}$ for 45 seconds and extension at $72{ }^{\circ} \mathrm{C}$ for 40 seconds), and the final extension at $72{ }^{\circ} \mathrm{C}$ for 7 minutes. S. pneumoniae (ATCC ${ }^{\circledR} 33400^{\mathrm{TM}}$ ) and $H$. influenzae $\left(\mathrm{ATCC}^{\circledR} 33391^{\mathrm{TM}}\right.$ ) standard strains were used as positive controls. Also, the E. coli $\mathrm{ATCC}^{\circledR} 11775^{\mathrm{TM}}$ and master mix without DNA template were used as two negative controls in each PCR run. The electrophoresis (100 $\mathrm{V}, 40 \mathrm{~min}$ ) was performed using a $1.5 \%$ agarose gel for the detection of amplified products.

\section{Capsular typing of $\boldsymbol{H}$. influenzae by PCR}

To differentiate encapsulated $H$. influenzae strains from NTHi strains, the bexA gene was amplified. Capsular typing performed using six specific primer sets which are listed in Table $1[19,20]$. The following standard strains were used for positive control: $H$. influenzae type a $\left(\mathrm{ATCC}^{\circledR} 9006^{\mathrm{TM}}\right)$, H. influenzae type b $\left(\mathrm{ATCC}^{\circledR} 9795^{\mathrm{TM}}\right.$ ), $H$. influenzae type c $\left(\mathrm{ATCC}^{\circledR} 9007^{\mathrm{TM}}\right)$, H. influenzae type d $\left(\right.$ ATCC $\left.^{\circledR} 9332^{\mathrm{TM}}\right), H$. influenzae type e $\left(\operatorname{ATCC}^{\circledR} 8142^{\mathrm{TM}}\right)$, and $H$. influenzae type $\mathrm{f}\left(\mathrm{ATCC}^{\circledR} 9833^{\mathrm{TM}}\right) . H$. influen$z a e$ isolates containing the $\operatorname{bex} A$ gene were considered as encapsulated $H$. influenzae and were further classified based on the presence of each of the capsular genes. The NTHi strains were those that lacking both bexA gene and any of the capsular genes. The PCR reactions composed of $0.5 \mu \mathrm{l}$ of each primer, $12.5 \mu \mathrm{l}$ of Mastermix [50 mM KCl, 10 mmol Tris- $\mathrm{HCl}$ (pH 8.3), $0.2 \mathrm{mM}$ each dNTP, $1.5 \mathrm{mM} \mathrm{MgCl}$, 1U Taq DNA polymerase] (Genet Bio, Korea), $5 \mu \mathrm{l}$ of template DNA, and DNA/RNA free water to reach the final volume of $25 \mu \mathrm{l}$. PCR conditions were as follows: an initial denaturation at $95^{\circ} \mathrm{C}$ for $5 \mathrm{~min}$, followed by 35 cycles of denaturation at $95{ }^{\circ} \mathrm{C}$ for $30 \mathrm{~s}$, annealing (Table 2) for $30 \mathrm{~s}$, extension at $72{ }^{\circ} \mathrm{C}$ for $30 \mathrm{~s}$, and final extension at $72{ }^{\circ} \mathrm{C}$ for $5 \mathrm{~min}$. The products of

Table 1 The primer sets used in this study

\begin{tabular}{|c|c|c|c|}
\hline Target & Primer sequence & Amplicon size & Reference \\
\hline lytA & $\begin{array}{l}\text { 5'-GGCTACTGGTACGTACATTC-3' } \\
\text { 5'-AATCAAGCCATCTGGCTCTA-3' }\end{array}$ & $395 b p$ & [18] \\
\hline P6 & $\begin{array}{l}\text { 5'- ACTTTTGGGGGTTACTCTGT-3' } \\
\text { 5'- TGTGCCTAATTTACCAGCAT-3' }\end{array}$ & $273 b p$ & [19] \\
\hline bexA & $\begin{array}{l}\text { HI-1-5'-CGTTTGTATGATGTTGATCCAGAC-3' } \\
\text { HI-2-5'-TGTCCATGTCTTCAAAATGATG-3' }\end{array}$ & $343 b p$ & [19] \\
\hline Type a & $\begin{array}{l}\text { a1-5'-CTACTCATTGCAGCATTTGC-3' } \\
\text { a2-5'-GAATATGACCTGATCTTCTG-3' }\end{array}$ & $250 \mathrm{bp}$ & [20] \\
\hline Type b & $\begin{array}{l}\text { b1-5'-GCGAAAGTGAACTCTTATCTCTC-3' } \\
\text { b2-5'-GCTTACGCTTCTATCTCGGTGAA-3' }\end{array}$ & $480 \mathrm{bp}$ & [20] \\
\hline Type c & $\begin{array}{l}\text { c1-5'-TCTGTGTAGATGATGGTTCA-3' } \\
\text { c2-5'-CAGAGGCAAGCTATTAGTGA-3' }\end{array}$ & $250 \mathrm{bp}$ & [20] \\
\hline Type d & $\begin{array}{l}\text { d1-5'-TGATGACCGATACAACCTGT-3' } \\
\text { d2-5'-TCCACTCTTCAAACCATTCT-3' }\end{array}$ & $150 \mathrm{bp}$ & [20] \\
\hline Type e & $\begin{array}{l}\text { e1-5'-GGTAACGAATGTAGTGGTAG-3' } \\
\text { e2-5'-GCTTTACTGTATAAGTCTAG-3' }\end{array}$ & $1350 \mathrm{bp}$ & [20] \\
\hline Type f & $\begin{array}{l}\text { f1-5'-GCTACTATCAAGTCCAAATC-3' } \\
\text { f2-5'-CGCAATTATGGAAGAAAGCT-3' }\end{array}$ & $450 \mathrm{bp}$ & [20] \\
\hline
\end{tabular}


Table 2 Test performance of multiplex polymerase chain reaction (M-PCR) in detection of Streptococcus pneumoniae and Haemophilus influenzae compared to culture method

\begin{tabular}{|c|c|c|c|c|c|c|}
\hline & \multicolumn{3}{|c|}{ Culture for Streptococcus pneumoniae } & \multicolumn{3}{|c|}{ Culture for Haemophilus influenzae } \\
\hline & Positive & Negative & Total & Positive & Negative & Total \\
\hline PCR Positive & $15(16.3 \%)$ & $18(19.5 \%)$ & $33(35.8 \%)$ & $7(7.6 \%)$ & $4(4.3 \%)$ & $11(11.9 \%)$ \\
\hline PCR Negative & $0(0.0 \%)$ & $59(64.2 \%)$ & $59(64.2 \%)$ & $0(0.0 \%)$ & $81(88.1 \%)$ & $81(88.1 \%)$ \\
\hline Total & $15(16.3 \%)$ & $77(83.7 \%)$ & $92(100 \%)$ & $7(7.6 \%)$ & $85(92.4 \%)$ & $92(100 \%)$ \\
\hline $\begin{array}{l}\text { Sensitivity (\%) } \\
(95 \% \mathrm{Cl})\end{array}$ & $100.0 \%$ (89.4 to $100.0 \%)$ & & & $100.0 \%$ (71.5 to $100.0 \%)$ & & \\
\hline $\begin{array}{l}\text { Specificity (\%) } \\
(95 \% \mathrm{Cl})\end{array}$ & $76.6 \%$ (65.6 to $85.5 \%)$ & & & $95.3 \%$ (88.4 to $98.7 \%)$ & & \\
\hline $\begin{array}{l}\text { Positive predictive value (\%) } \\
(95 \% \mathrm{Cl})\end{array}$ & $64.7 \%$ (55.0 to $73.3 \%)$ & & & $73.3 \%$ (51.4 to $87.7 \%)$ & & \\
\hline $\begin{array}{l}\text { Negative predictive value (\%) } \\
(95 \% \mathrm{Cl})\end{array}$ & $100.0 \%$ & & & $100.0 \%$ & & \\
\hline $\begin{array}{l}\text { Positive likelihood ratio (\%) } \\
(95 \% \mathrm{Cl})\end{array}$ & $4.3 \%$ (2.9 to $6.4 \%)$ & & & $21.3 \%$ (8.2 to $55.3 \%)$ & & \\
\hline $\begin{array}{l}\text { Negative likelihood ratio (\%) } \\
(95 \% \mathrm{Cl})\end{array}$ & $0.0 \%$ & & & $0.0 \%$ & & \\
\hline $\begin{array}{l}\text { Test accuracy }(\%) \\
(95 \% \mathrm{Cl})\end{array}$ & $83.6 \%$ (75.4 to $90.0 \%)$ & & & $95.8 \%$ (89.7 to $98.9 \%)$ & & \\
\hline
\end{tabular}

each PCR assay were analyzed by gel electrophoresis on $1.5 \%$ agarose.

\section{Statistical analysis}

The descriptive statistic tests were performed in SPSS version 21.0 (Armonk, NY, USA), and a level of significance of $P$-value $<0.05$ was used. Continuous data was compared using $95 \%$ confidence intervals $(\mathrm{CI})$.

\section{Results}

Prevalence of S. pneumoniae and $H$. influenzae isolates by culture and M-PCR

A total of 92 sputum samples were collected from 50 (54.3\%) males and 42 (45.7\%) females suffered from CAP. The patients' ages ranged from 25 to 93 with the mean age of 59 years. Out of 92 sputum samples, 22 (23.9\%) were culture positive, from which 15 (16.3\%) and 7 (7.6\%) samples were positive for S. pneumoniae and H. influen$z a e$, respectively. Among the 92 samples, 44 (47.8\%) were positive in M-PCR analysis, from which 33 (35.8\%), 11 (11.9\%), and 3 (3.2\%) samples were positive for S. pneumoniae, $H$. influenzae, and both pathogens, respectively. The detection rates of both pathogens were much higher in M-PCR method compared to the culture method ( $P$ $<0.005$ ) (Table 2). The sensitivity, specificity, and accuracy rates of M-PCR in detection of S. pneumoniae in comparison with culture method were 100, 76.6, and $83.6 \%$, respectively. While, the sensitivity, specificity, and accuracy rates of PCR in detection of $H$. influenzae in comparison with culture method were 100, 95.3, and $95.8 \%$, respectively.

\section{Capsular typing of $H$. influenzae}

All 11 positive samples of $H$. influenzae in M-PCR were evaluated by another run of PCR amplification for the bex $A$ and capsular genes $(a, b, c, d, e$ and $f)$. Out of 11 isolates of $H$. influenzae, two strains containing both the bexA gene and capsular gene $\mathrm{b}$ and confirmed as Hib strains. Three isolates showed the bexA and capsular gene $\mathrm{f}$ amplification. However, 6 isolates lacking both bexA and any of the capsular genes and were considered as NTHi.

\section{Antimicrobial susceptibility patterns}

The antibiotic susceptibility patterns of the S. pneumonia and $H$. influenzae isolates are shown in Table 3. Ceftriaxone and co-trimoxazole with 13.3 and $73.3 \%$ of resistance rates were the most and the less effective antibiotics against S. pneumoniae, respectively. Clarithromycin, ceftriaxone, and gentamicin with resistance rates of $28.6 \%$ for each one were the most effective chemicals against $H$. influenzae isolates. While, the amoxicillin/clavulanate (resistance rate $85.7 \%$ ) was the weakest drug.

\section{Discussion}

Conventional methods, such as culture and serology are not always adequate to detect CAP pathogens. Rapid diagnosis of etiologic agents of CAP based on 
Table 3 Sensitivity patterns of Streptococcus pneumoniae and Haemophilus influenza isolates

\begin{tabular}{llll}
\hline Antimicrobial agents & Susceptible/Resistant & $\begin{array}{l}\text { S. pneumoniae } \\
(\boldsymbol{n}=15)\end{array}$ & $\begin{array}{l}\text { H. influenzae } \\
(\boldsymbol{n}=7)\end{array}$ \\
\hline Ciprofloxacin & $\mathrm{S}$ & Not recommended by CLSI & $3(42.9 \%)$ \\
Amoxicillin/clavulanate & $\mathrm{R}$ & $10(66.7 \%)$ & $4(57.1 \%)$ \\
& $\mathrm{S}$ & $5(33.3 \%)$ & $6(14.3 \%)$ \\
Clarithromycin & $\mathrm{R}$ & $6(40 \%)$ & $5(71.4 \%)$ \\
& $\mathrm{S}$ & $9(60 \%)$ & $2(28.6 \%)$ \\
Ceftriaxone & $\mathrm{R}$ & $13(86.7 \%)$ & $5(71.4 \%)$ \\
& $\mathrm{S}$ & $2(13.3 \%)$ & $2(28.6 \%)$ \\
Co- trimoxazole & $\mathrm{R}$ & $4(26.7 \%)$ & $4(57.1 \%)$ \\
& $\mathrm{S}$ & $11(73.3 \%)$ & $3(42.9 \%)$ \\
Erythromycin & $\mathrm{R}$ & $7(46.7 \%)$ & Not recommended by CLSI \\
\hline
\end{tabular}

CLSI Clinical and laboratory standards institute

phenotypic methods is difficult; therefore, new diagnosis methods are needed [21]. It is well known that sensitivity and specificity of routine culture is low for identification of CAP pathogens. Thus, more sensitive and rapid diagnostic methods, such as molecular method, could possibly be useful for detect of CAP pathogens [22].

In this study, both culture and M-PCR methods were used for detection of two bacterial causes (S. pneumoniae and $H$. influenzae) of CAP. The results showed that the detection rate of M-PCR method (47.8\%) was higher than culture method [23.9\%]. In line with these findings, Maleki et al. [23] from Iran showed the superiority of molecular techniques such as real-time PCR than culture in detection of S. pneumoniae and H. influenzae from oropharynx and nasal cavity. Also, in another study by et al. [24] from United Kingdom, the detection rates of molecular method were $9.4-26.2 \%$ higher than culture for S. pneumoniae, Moraxella catarrhalis, and $H$. influenzae that was in agreement with this study. Also, in this study the accuracy rate of M-PCR in detection of $H$. influenzae was higher than S. pneumoniae that was in line with the previous study by Bjarnason et al. [25] from Iceland.

This study revealed a $100 \%$ sensitivity of M-PCR in detection of $H$. influenzae and S. pneumoniae compared to culture method. In contrast to the current research, Gillis et al. [26] showed that PCR based method had poor sensitivity in detection of $S$. pneumoniae in nasopharyngeal swabs of CAP patients. This discrepancy may be due to the differences in sample types, as we used sputum samples in the current study. The M-PCR method had lower specificity in detection of S. pneumoniae than $H$. influenzae in this study. Due to the existence of autolysin gene $(l y t A)$ in other oral flora streptococci, this crossreactivity may be reduce the M-PCR specificity for detection of S. pneumoniae in sputum samples [25]. Shakib et al. [27] from Iran showed the $100 \%$ sensitivity of realtime PCR for detection of S. pneumoniae in sputum samples using the lytA gene that was similar to our results. In another study by Fan et al. [28] from China, a one-step M-PCR assay detecting the ompP6 and the bexA genes of $H$. influenzae was compared with culture and serum agglutination test. The results of M-PCR showed the sensitivity and specificity of 100 and $99.8 \%$, respectively. This findings were close to our results that exhibited a sensitivity of $100 \%$ and the specificity of $95.3 \%$ of M-PCR in detection of $H$. influenzae.

In this study the culture method revealed prevalence rates of 16.3 and $7.6 \%$ for S. pneumoniae and H. influen$z a e$, respectively. Using culture method, prevalence rates of $6.5 \%$ from Iran [23], 16\% from Iceland [25], and $18.4 \%$ from China [28] has been reported in previous reports for $H$. influenzae. Also, occurrence rates of $11.4 \%$ from Iran [23] and 20\% from Iceland [25] has been reported for S. pneumoniae in previous researches. According to the study of Aydemiret et al. [29] from Turkey, the isolation rates of S. pneumoniae and $H$. influenzae from sputum, nasopharyngeal swabs and bronchoalveolar lavage (BAL) fluid samples by culture method were 16.2 and $0.0 \%$, respectively. This frequency rate of $S$. pneumonia was similar to the current study. In contrast to the current study, Costa et al. [6] from Portugal, reported a higher frequency rates of $H$. influenzae (21.4\%) than $S$. pneumoniae $(14.1 \%)$ in sputum/BAL samples using culture method.

In the current research, using M-PCR method, the incidence rates of $35.8,11.9$, and $3.2 \%$ were revealed 
for S. pneumoniae, H. influenzae, and both pathogens, respectively. Fan et al. [28] from China reported a higher prevalence (19.3\%) for $H$. influenzae in nasopharyngeal secretion of Children suffered from respiratory infections. Aydemir et al. [29] from Turkey, reported frequency rates of 15.2, 12.7, and $14.7 \%$ for S. pneumoniae, $H$. influenzae, and both pathogens coinfection, respectively. In a study from United Kingdom [30], more $H$. influenzae (40.2\%) was detected than S. pneumoniae (35.6\%) in patients with CAP that was in contrast to the current results. So far, scarce studies have examined the prevalence of CAP-related pathogens in Iran, most of which focus on only a small number of bacterial or viral pathogens. In a study by Naderi et al. [31] from Mashhad, Iran, the S. pneumoniae (24.4\%) was the most prevalent pathogen in CAP patients using conventional culture method and standard BACTEC device. However, they reported a lower prevalence rate for S. pneumoniae than our study. Also, inconsistent to the current research, Temesgen et al. [32] from Ethiopia, reported higher prevalence rates for S. pneumoniae (35.9\%) and H. influenzae (8.4\%) using conventional culture and biochemical tests. These variations among several studies can be due to differences in geographical area, type of detection method, sample size, type of studied sample, and age range of the study population.

Another finding of the current study was the prevalence rates of 2.1 and $6.5 \%$ for Hib and NTHi using PCR method, respectively. Also, $3.2 \%$ of isolates were $H$. influenzae type f. Our results were consistent with previous evidence that reported a 2 to $12 \%$ prevalence of CAP due to NTHi [10]. Hib is a leading cause of serious illness in children under the age of 5 . Previous report from Iran showed the prevalence rate of $8 \%$ for Hib in clinical samples [20]. The present study is one of a handful of studies that examined the prevalence of different capsular types of $H$. influenzae in Iran. In this study, a, c, d, and e types were not observed. In another study from Iran, the $\mathrm{b}$, e, and $\mathrm{f}$ capsular types were reported in $\mathrm{H}$. influenzae isolates [33]. There has been evidence from both developed and developing countries that introducing the Hib vaccination has reduced its carrier numbers. In November 2014, the pentavalent vaccine which contains diphtheria, tetanus, whole cell pertussis, hepatitis B, and $H$. influenzae type $\mathrm{b}$ entered the Iranian National Immunization Plan. Vaccination against Hib may reduce Hib colonization, while increasing other serotypes $[8,34]$ The technique used to identify the $H$. influenzae capsular type may affect the results. Because in some studies, slide agglutination serotyping-based methods and in some others the molecular methods are used [33].

One of the strength of the current study was the determination of antibiotic resistance patterns of $S$. pneumoniae and $H$. influenzae isolates against some routine antibiotics. S. pneumoniae showed most susceptibility against ceftriaxone (86.7\%) and amoxicillin/ clavulanate (66.7\%) which was in agreement with previous studies by Temesgen et al. [32] and Akter et al. [35] who showed the good efficacy of two aforesaid antibiotics against S. pneumoniae. However, the co-trimoxazole with susceptibility rate of $26.7 \%$ was the less effective antibiotic against S. pneumoniae. Conversely, Temesgen et al. [32] reported an $8.3 \%$ of resistance rate among S. pneumoniae isolates toward the co-trimoxazole. In another study from Iran, the susceptibility rates of $S$. pneumoniae isolates in patients with non-meningitis invasive disease were 90.4 and $33.3 \%$ for ceftriaxone and co-trimoxazole, respectively [36]. Also, the susceptibility rates of $S$. pneumoniae isolates for erythromycin and clarithromycin were 46.7 and $40 \%$, respectively. The sensitivity rate for erythromycin was higher than a previous report by Houri et al. [36] from Iran who stated the rate of $23.8 \%$, but lower than a report by Temesgen et al. [32] who showed susceptibility rate of $96.7 \%$. However, in a study by Zhao et al. [37] from China, 95.2 and $92.5 \%$ of $S$. pneumoniae isolates were resistant to erythromycin and clarithromycin, respectively. S. pneumoniae is mainly treated with beta-lactams and macrolides, while fluoroquinolones occupied the third treatment choice. There is a major concern in the world regarding beta-lactams and macrolides resistant S. pneumoniae isolates. S. pneumoniae was recently ranked among the 12 bacteria for which new treatments are severely needed by the World Health Organization [38].

The current research showed the good efficacy of clarithromycin and ceftriaxone (more than 70\%) against $H$. influenzae isolates. While, the amoxicillin-clavulanate (resistance rate 85.7\%) was the weakest treatment choice. In a previous study by Shooraj et al. [39] from Iran the susceptibility rate of $80 \%$ was reported for ceftriaxone that was almost close to this research. Also, our isolates showed the resistance rates of 57.1 , and $42.9 \%$ for ciprofloxacin and co-trimoxazole, respectively. In contrast to the current study, Shooraj et al. [39] stated the quinolones as the most effective antibiotics against $H$. influen$z a$ e. Also, they showed a higher resistance rate (57.7\%) for co-trimoxazole compared to our findings. In another study by Boroumand et al. [40] from Iran, all $H$. influenza isolates were sensitive to co-trimoxazole. Also, they reported resistance rates of 50 and $45 \%$ for ceftriaxone and ciprofloxacin, respectively. In a recent meta-analysis from Iran, the resistance rates of $H$. influenzae to various antibiotics were as follows: co-trimoxazole $53 \%$, erythromycin $40.3 \%$, ciprofloxacin $30.8 \%$, ceftriaxone $33.1 \%$, and amoxicillin-clavulanate $11.8 \%$. As it is obvious, the rate of amoxicillin-clavulanate resistance in the current study 
was much higher than the Iranian average. Also, our results were in contrast to previous reported resistance rate for amoxicillin-clavulanate (0.0\%) from Ethiopia [32]. Also, in the later study [32], a lower and an equal resistance rates were reported against ciprofloxacin (35.7\%) and ceftriaxone $(28.6 \%)$ against $H$. influenzae isolates compared to the current research.

\section{Limitations}

It is important to acknowledge some limitations of this study. This research could not include all clinical and high risk parameters of patients that may affect the etiology of CAP infection. Also, the focus of this study was based on the prevalence of S. pneumoniae and $H$. influenzae. Hence, the other bacterial or viral pathogens were not investigated in CAP patients. Also, this study was limited to CAP patients who produced sputum and no blood cultures and urinary antigen test were included. Sputum is still an effective specimen type when investigating CAP microbiologically, despite its shortcomings.

\section{Conclusions}

In this study, the M-PCR showed good sensitivity and specificity compared to culture method in detection of $H$. influenzae and S. pneumoniae in sputum samples of CAP patients. The M-PCR provided better efficiency in detecting the bacterial agents in CAP patients compared to culture method. It is recommended that this technique be used in addition to the culture method in the detection of pathogens involved in the CAP infection. Also, the prevalence of S. pneumoniae was higher than $H$. influenzae in CAP patients. The Hib was detected in $2.1 \%$ of patients. The $H$. influenzae and S. pneumoniae isolates showed various resistance rates against studied antibiotics. The drug resistant S. pneumoniae and $H$. influenzae indicated the need to develop a codified monitoring program to prevent further spread of these strains.

\section{Abbreviations \\ CAP: Community-acquired pneumonia; CLSI: Clinical Laboratory Standard Institute; Hib: Haemophilus influenzae type b; M-PCR: Multiplex polymerase chain reaction; NTHi: Non-typeable Haemophilus influenzae.}

\section{Acknowledgements}

This work was a part of MSc thesis of Robab Rahimi. The initial proposal of the work was discussed and approved by the Ethics Committee and Cardiovascular Research Center, Ahvaz Jundishapur University of Medical Sciences, Ahvaz, Iran (IR.AJUMS.REC.1394.458)

\section{Authors' contributions}

A.F.S and R.R. designed the studies. R.R. performed bacterial identification, antibacterial susceptibility testing, and M-PCR. H.M., A.A., and M.S. analyzed the data. H.M., A.A., and M.S. wrote the manuscript with contributions from all authors. H.M., A.A., and M.S. revised the manuscript. All authors contributed to data analysis, drafting and critically revising the paper and agree to be accountable for all aspects of the work. The author(s) read and approved the final manuscript.

\section{Funding}

This study was financially supported by the Ethics Committee and Cardiovascular Research Center Ahvaz Jundishapur University of Medical Sciences, Ahvaz, Iran (grant no: CVRC-9410).

\section{Availability of data and materials}

All data generated or analyzed during this study are included here and are available from the corresponding author on reasonable request.

\section{Declarations}

\section{Ethics approval and consent to participate}

This study was approved by the Research Ethics Committee and Cardiovascular Research Center (IR.AJUMS.REC.1394.458) of the Ahvaz Jundishapur University of Medical Sciences, Ahvaz, Iran following the Declaration of Helsinki. Written informed consent was obtained from each patient before collecting sputum samples.

\section{Consent for publication \\ Not applicable.}

\section{Competing interests}

The authors declare that they have no competing interests.

\section{Author details}

${ }^{1}$ Department of Microbiology, Faculty of Medicine, Ahvaz Jundishapur University of Medical Sciences, Ahvaz, Iran. ${ }^{2}$ Infectious and Tropical Diseases Research Center, Health Research Institute, Ahvaz Jundishapur University of Medical Sciences, Ahvaz, Iran. ${ }^{3}$ Student Research Committee, Ahvaz Jundishapur University of Medical Sciences, Ahvaz, Iran.

Received: 10 August 2021 Accepted: 2 December 2021

Published online: 14 December 2021

\section{References}

1. Severiche-Bueno D, Parra-Tanoux D, Reyes LF, Waterer GW. Hot topics and current controversies in community-acquired pneumonia. Breathe. 2019;15(3):216-25.

2. Kolditz M, Ewig S. Community-acquired pneumonia in adults. Dtsch Arztebl Int. 2017;114(49):838-48.

3. Torres A, Cilloniz C, Niederman MS, Menéndez R, Chalmers JD, Wunderink RG, et al. Pneumonia. Nat Rev Dis Primers. 2021;7:25.

4. Shoar S, Musher DM. Etiology of community-acquired pneumonia in adults: a systematic review. Pneumonia. 2020;12(1):11.

5. Abdoli S, Safamanesh S, Khosrojerdi M, Azimian A. Molecular detection and serotyping of Streptococcus pneumoniae in children with suspected meningitis in Northeast Iran. Iran J Med Sci. 2020;45(2):125-33.

6. Costa MI, Cipriano A, Santos FV, Valdoleiros SR, Furtado I, Machado A, et al. Clinical profile and microbiological etiology diagnosis in adult patients hospitalized with community-acquired pneumonia. Pulmonology. 2020;S2531-0437(20):30246-54.

7. Thofte O, Su YC, Brant M, Littorin N, Duell BL, Alvarado V, et al. EF-Tu from non-typeable Haemophilus influenzae is an immunogenic surfaceexposed protein targeted by bactericidal antibodies. Front Immunol. 2018;9:2910.

8. Tabatabaei SR, Mohammadzadeh S, Zahraei SM, Mahmoudi S, Ghandchi G, Hoseini-Alfatemi SM, et al. Effect of Haemophilus influenzae type b vaccination on nasopharyngeal carriage rate in children, Tehran, 2019. Biomed Res Int. 2021;2021:4923852.

9. Slack M, Esposito S, Haas H, Mihalyi A, Nissen M, Mukherjee P, et al. Haemophilus influenzae type b disease in the era of conjugate vaccines: critical factors for successful eradication. Expert Rev Vaccines. 2020;19(10):903-17.

10. Vaez H, Sahebkar A, Pourfarzi F, Yousefi-Avarvand A, Khademi F. Prevalence of antibiotic resistance of Haemophilus Influenzae in Iran-a metaanalysis. Iranian J Otorhinolaryngol. 2019;31(107):349-57.

11. Tang M, Wang D, Tong X, Wu Y, Zhang J, Zhang L, et al. Comparison of different detection methods for Mycoplasma pneumoniae infection 
in children with community-acquired pneumonia. BMC Pediatr. 2021;21(1):1-8.

12. Giuliano C, Patel CR, Kale-Pradhan PB. A guide to bacterial culture identification and results interpretation. PT. 2019;44(4):192-200.

13. Rajapaksha P, Elbourne A, Gangadoo S, Brown R, Cozzolino D, Chapman J. A review of methods for the detection of pathogenic microorganisms. Analyst. 2019;144(2):396-411.

14. Zhao W, Pan F, Wang B, Wang C, Sun Y, Zhang T, et al. Epidemiology characteristics of Streptococcus pneumoniae from children with pneumonia in Shanghai: a retrospective study. Front Cell Infect Microbiol. 2019;9:258.

15. Su PY, Huang $A H$, Lai $C H$, Lin HF, Lin $T M$, Ho CH. Extensively drug-resistant Haemophilus influenzae-emergence, epidemiology, risk factors, and regimen. BMC Microbiol. 2020;20:102.

16. Mahon CR, Lehman DC, Manuselis JG. Textbook of diagnostic microbiology. Amsterdam: Elsevier Health Sciences; 2014.

17. Clinical and Laboratory Standards Institute (CLSI). Performance Standards for Antimicrobial Susceptibility Testing. 27th ed. CLSI supplement M100 (ISBN 1-56238-804-5 [Print]; ISBN 1-56238-805-3 [Electronic]). Clinical and Laboratory Standards Institute, 950 West Valley Road, Suite 2500, Wayne, Pennsylvania 19087 USA, 2017.

18. Albuquerque RC, Moreno AC, Dos Santos SR, Ragazzi SL, Martinez MB. Multiplex-PCR for diagnosis of bacterial meningitis. Br J Microbiol. 2019;50(2):435-43.

19. de Filippis I, Andrade CF, Caldeira N, Azevedo AC, Almeida AE. Comparison of PCR-based methods for the simultaneous detection of Neisseria meningitidis, Haemophilus influenzae, and Streptococcus pneumoniae in clinical samples. Br J Infect Dis. 2016:20:335-41.

20. Bagherzadeh Khodashahri S, Siadat SD, Rahbar M, AbdollahpourAlitappeh M, Vaziri F, Rahnamaye-Farzami M, et al. Genotyping of Haemophilus influenzae type $b$ strains and their incidence in the clinical samples isolated from Iranian patients. Iran J Microbiol. 2015;7(3):136-43.

21. Goodarzi NN, Pourmand MR, Rajabpour M, Arfaatabar M, Mosadegh M, Mohamad SS. Frequency of Mycoplasma pneumoniae, Legionella pneumophila and Chlamydia spp. among patients with atypical pneumonia in Tehran. New Microb New Infect. 2020;37:100744.

22. Lim HJ, Kang E-R, Park MY, Kim BK, Kim MJ, Jung S, et al. Development of a multiplex real-time PCR assay for the simultaneous detection of four bacterial pathogens causing pneumonia. PLoS ONE. 2021;16(6):e0253402.

23. Maleki A, Mansournia F, Ghafourian S, Taherikalani M, Pakzad I, Mohammadi J, et al. Rapid and direct molecular detection of Streptococcus pneumoniae and Haemophilus influenzae isolated in oropharynx and nasal cavity of children. New Microbes New Infect. 2020:33:100632.

24. Thors V, Morales-Aza B, Pidwill G, Vipond I, Muir P, Finn A. Population density profiles of nasopharyngeal carriage of 5 bacterial species in pre-school children measured using quantitative PCR offer potential insights into the dynamics of transmission. Hum Vaccin Immunother. 2016;12(2):375-82.

25. Bjarnason A, Lindh M, Westin J, Andersson LM, Baldursson O, Kristinsson KG, et al. Utility of oropharyngeal real-time PCR for S. pneumoniae and $H$. influenzae for diagnosis of pneumonia in adults. Eur $J$ Clin Microbiol Infect Dis. 2017:36(3):529-36.

26. Gillis HD, Lang AL, EISherif M, Martin I, Hatchette TF, McNeil SA, et al. Assessing the diagnostic accuracy of PCR-based detection of Streptococcus pneumoniae from nasopharyngeal swabs collected for viral studies in Canadian adults hospitalised with community-acquired pneumonia: a Serious Outcomes Surveillance (SOS) Network of the Canadian Immunization Research (CIRN) study. BMJ Open. 2017;7(6):e015008.

27. Shakib P, Zolfaghari MR. Detection of Streptococcus pneumoniae in sputum samples by real-time PCR. Anti-Infect Agents. 2021;19(1):117-21.

28. Fan $X$, Liu X, Ji L, Cai D, Jiang J, Zhu J, et al. Epidemiological analysis and rapid detection by one-step multiplex PCR assay of Haemophilus influenzae in children with respiratory tract infections in Zhejiang Province, China. BMC Infect Dis. 2018;18(1):1-6.

29. Aydemir O, Aydemir Y, Ozdemir M. The role of multiplex PCR test in identification of bacterial pathogens in lower respiratory tract infections. Pakistan J Med Sci. 2014;30(5):1011.

30. Gadsby NJ, Russell CD, McHugh MP, Mark H, Conway Morris A, Laurenson IF, et al. Comprehensive molecular testing for respiratory pathogens in community-acquired pneumonia. Clin Infect Dis. 2016;62(7):817-23.

31. Naderi H, Sheybani F, Sarvghad M, Meshkat Z, Jabbari Nooghabi M. Etiological diagnosis of community-acquired pneumonia in adult patients: a prospective hospital-based study in Mashhad, Iran. Jundishapur J Microbiol. 2015;8(8):e22780.

32. Temesgen D, Bereded F, Derbie A, Biadglegne F. Bacteriology of community acquired pneumonia in adult patients at Felege Hiwot Referral Hospital, Northwest Ethiopia: a cross-sectional study. Antimicrob Resist Infect Control. 2019;8(1):1-8.

33. Mojgani N, Rahbar M, Taqizadeh M, Ashtiani MP, Mohammadzadeh M Biotyping, capsular typing, and antibiotic resistance pattern of Haemophilus influenzae strains in Iran. Jpn J Infect Dis. 2011;64(1):66-8.

34. Shirvani F, Arjmand R, Golami M, Najafi Tavana E, Saee Rad S, et al. Oropharyngeal colonization of Haemophilus influenzae type $b$ and serologic response after administration of third dose of pentavalent vaccine to 12 -month-old children in Karaj, Iran. Arch Pediatr Infect Dis. 2016;7(1):e82238.

35. Akter S, Shamsuzzaman S, Jahan F. Community acquired bacterial pneumonia: aetiology, laboratory detection and antibiotic susceptibility pattern. Malaysian J Pathol. 2014;36(2):97-103.

36. Houri H, Tabatabaei SR, Saee Y, Fallah F, Rahbar M, Karimi A. Distribution of capsular types and drug resistance patterns of invasive pediatric Streptococcus pneumoniae isolates in Teheran, Iran. Int J Infect Dis. 2017;57:21-6.

37. Zhao C, Li Z, Zhang F, Zhang X, Ji P, Zeng J, et al. Serotype distribution and antibiotic resistance of Streptococcus pneumoniae isolates from 17 Chinese cities from 2011 to 2016. BMC Infect Dis. 2017;17(1):804.

38. Cillóniz C, Garcia-Vidal C, Ceccato A, Torres A. Antimicrobial resistance among Streptococcus pneumoniae. Antimicrobial resistance in the 21st century. 2018:13-38.

39. Shooraj F, Mirzaei B, Mousavi SF, Hosseini F. Clonal diversity of Haemophilus influenzae carriage isolated from under the age of 6 years children. BMC Res Notes. 2019;12(1):565.

40. Boroumand M, Irani S, Siadat SD, Bouzari S. Molecular detection of genomic islands associated with class 1 and 2 integron in Haemophilus influenzae isolated in Iran. Jundishapur J Microbiol. 2015;8(4):e17249.

\section{Publisher's Note}

Springer Nature remains neutral with regard to jurisdictional claims in published maps and institutional affiliations.

Ready to submit your research? Choose BMC and benefit from

- fast, convenient online submission

- thorough peer review by experienced researchers in your field

- rapid publication on acceptance

- support for research data, including large and complex data types

- gold Open Access which fosters wider collaboration and increased citations

- maximum visibility for your research: over $100 \mathrm{M}$ website views per year

At BMC, research is always in progress.

Learn more biomedcentral.com/submissions 